\title{
Design and experimental study of electrical and mechanical brake for mine hoist
}

\author{
Huawei Jin ${ }^{1,2,3,4, *}$, Huanyu Huo ${ }^{1,2,3,4}$, Chuanli Wang ${ }^{1,4}$, Shun Wang ${ }^{1,2,3,4}$, and Huwei Xu ${ }^{1,2,3,4}$ \\ ${ }^{1}$ State Key Laboratory of Mining Response and Disaster Prevention and Control in Deep Coal Mines, Anhui University \\ of Science and Technology, Huainan 232001, China \\ ${ }^{2}$ State Key Laboratory of Coal Resources in Western China, Key Laboratory of Western Mine Exploitation and Hazard \\ Prevention, Ministry of Education, Xi'an University of Science and Technology, Xi'an 710054, China \\ ${ }^{3}$ Institute of Environment Friendly Materials and Occupational Health Anhui University of Science and Technology, Wuhu \\ 241003, China \\ 4 Anhui Key Laboratory of Mine Intelligent Equipment and Technology, Anhui University of Science and Technology, Huainan \\ 232001, China
}

Received: 3 December 2020 / Accepted: 26 April 2021

\begin{abstract}
To meet the requirement of the braking response of the coal mine hoist, a new electromechanical braking technology for mine hoists is proposed, the principle of electromechanical braking of mine hoists is demonstrated, and the detailed parameters and braking performance of electromechanical brakes are given. Index, an electromechanical brake test platform with large load and high response is developed. Experiments show that the maximum positive pressure of the designed electromechanical brake reaches $33 \mathrm{KN}$, which meets the requirement of positive pressure of mine hoist. The braking error is less than $10 \%$, and the braking gap elimination time is less than $0.1 \mathrm{~s}$. There is a linear relationship between motor current input and brake positive pressure output, with a slope of 4.17 and an intercept of 0.62 . The screw displacement output and the brake pressure output have a cubic relationship, and the zero error is small. Through research, a new idea is provided for the development of electromechanical brakes for coal mine hoist.
\end{abstract}

Keywords: Mine hoist / electromechanical brake / braking response / braking force / experimental research

\section{Introduction}

As a key transportation equipment connecting the ground and underground facilities in mine production, the mine hoist is directly related to the safe operation of the equipment, and thus affects the safe production of the entire mine. And the braking system is the top priority of the hoist system. Especially, when an emergency braking situation occurs, it plays a decisive role in controlling the hoist in time and effectively. In order to ensure the sustainable, healthy and safe development of coal energy, it is imperative to improve the technical level of the braking system and improve the response characteristics of the braking system [1].

At present, the braking of mine hoists is mostly based on electro-hydraulic technology, and the hydraulic braking technology adopted is relatively mature. The research

\footnotetext{
* e-mail: hwjin@mail.ustc.edu.cn
}

carried out by scholars from various countries has also achieved remarkable results, Zhang et al. [2] proposed that the disc brake applied in civil engineering uses the preload of the disc spring to force the piston to press the brake disc, meanwhile, make the brake pad and the brake disc contact to generate braking torque. When the pressure of hydraulic oil increasing, the brake pads move backward to realize the brake is released. Wang et al. [3] analyzed that the electrohydraulic proportional relief valve is more stable than the traditional nozzle baffle and electro-hydraulic proportional directional valve, the model of g-bridge electro-hydraulic proportional relief valve is completed by AMESim simulation software, and the pressure characteristic curve of relief valve port is obtained. Wang et al. [4] controlled the oil pressure of the disc brake by dynamic regulating the pressure of the electro-hydraulic proportional relief valve, and controlling the size of the braking torque, which laid a solid foundation for further research. Ungureanu et al. [5] completed the measurement of the wear strength based on the initial speed of the brake rim, surface roughness and 
contact pressure of the brake tread, finally he improved the service life of the brake. In terms of brake friction, Kumar et al. [6] prepared three non-asbestos organic (NAO) friction composites with iron, copper, and brass as fillers. Tests showed that the iron powder composites have the best effect. Da Gang Wang et al. [7] studied dynamic characteristics of the brake of a kilometer mine hoist during emergency braking, the three-dimensional thermo mechanical coupling finite element model of disc brake shoe is established, and analyzed the influence of temperature field on emergency braking. Masoomi et al. [8] proposed to use a friction material with thermal modulus to improve the braking performance of the hoist. Zhang et al. [9] proposed a new type of disc brake and conducted an experiments with DSF sensor and PBP sensor, it showed that the realtime monitoring of DSF, PBP and other parameters have lower errors. $\mathrm{Xu}$ et al. [10] have manufactured an experimental prototype of disc brake with the functions of real-time monitoring braking force and diagnosing the brake fault.

However, the response characteristics, lifting efficiency, and effective load rate of traditional mine hoists cannot meet the needs of ultra-deep mine hoists. At the same time, the hydraulic brake system has a complicated hydraulic circuit [11], and there may be hydraulic oil leakage and hydraulic oil deterioration and other issues [12-15]. In order to adapt to new demands, it is necessary to adopt new braking technology. The survey found that the field of aerospace [16-18], automotive and other fields have already carried out electromechanical braking technology research. German Continental Tweiss et al. [19,20] used a motor to drive a bevel gear one-stage reduction mechanism, and then used a ball screw pair to complete the axial thrust effect. Bosch uses an electromagnetic clutch to achieve rapid feed, and a two-stage reduction gear mechanism completes the boosting of the brake shoe. Siemens VDO uses a built-in motor to directly drive the ball screw, and uses a lever booster mechanism to replace the first-level gear reduction mechanism. The Swedish company Haldex [21] has developed a compact integrated electromechanical brake wheel module and will be used in the European Union Civil Robot Research and Development Program (SPARC). American GM, Italian Bertone, French Citroen, Japanese Denso, Advics, Nissan DENG, et al. [22,23] have also studied electromechanical brake actuators and developed their own prototypes. Some companies have already carried out actual vehicle tests. It can be seen from the above that electromechanical braking technology has the advantages of excellent performance, no brake fluid, rapid response, safety, environmental protection and is particularly suitable for the research of coal mine brake systems. Although the use of electromechanical braking technology is also a more feasible braking solution, from the public literature, the application of this technology in the field of mine hoist braking has not attracted enough attention from researchers.

In this paper, an electromechanical brake for mine hoists is developed based on the working principle of the mine hoist brake system, and starting from saving the manufacturing cost of the brake, the design process of the brake is given. Developed brake test bench with large

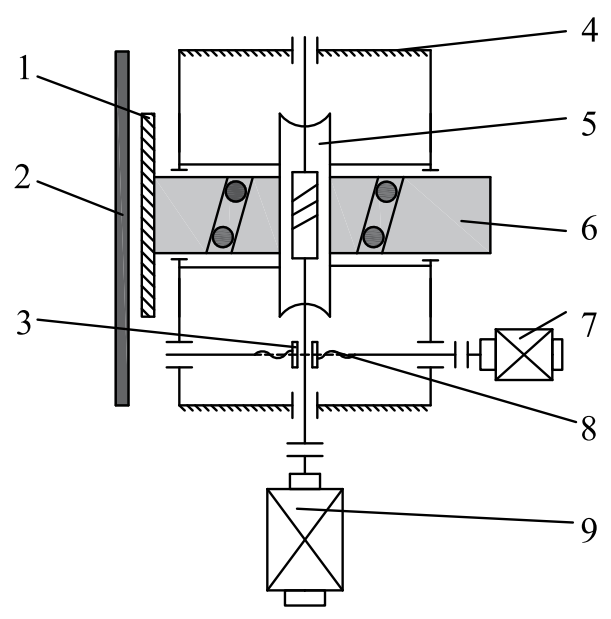

Fig. 1. Structure diagram of electromechanical brake. 1. Brake disc; 2. Brake tread; 3. Clamp block; 4. Box; 5. Worm gear; 6. Ball screw pair; 7. Stepper motor; 8. Trapezoidal screw; 9. Torque motor.

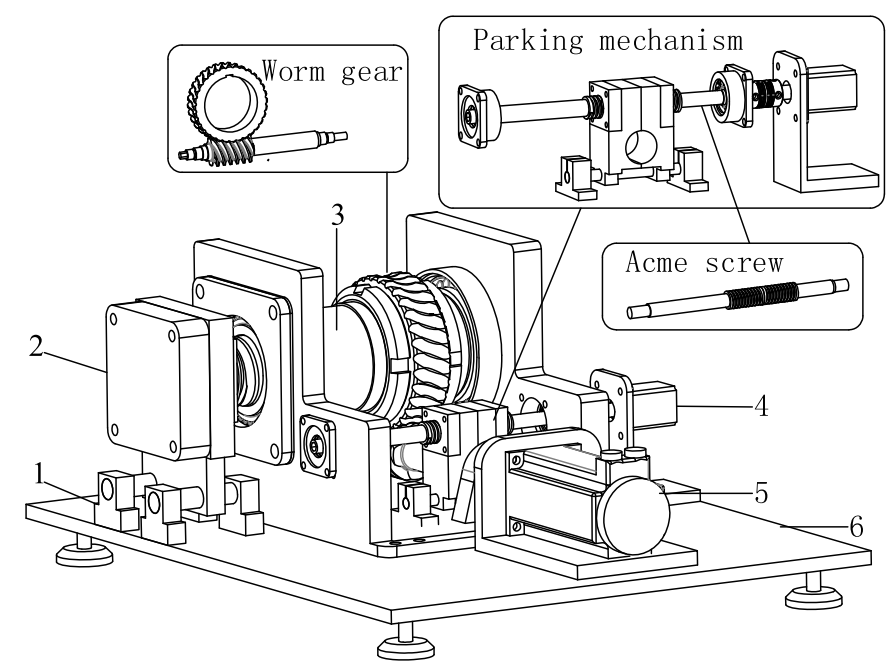

Fig. 2. Design drawing of electromechanical brake. 1. Linear guides. 2. Brake tread. 3. Ball screw pair. 4. Stepper motor. 5. Torque motor. 6. Support plate.

load and high response. The relationship between output brake pressure and voltage and screw displacement output is obtained, which provides a new idea for the development of electromechanical brakes for coal mine hoists in the future.

\section{Working principle and design development of electromechanical brake}

\subsection{Working principle}

The structure of electromechanical brake developed in this paper is shown in Figure 1, and design drawing is shown in Figure 2. Electromechanical brake is mainly composed of an actuator and a parking mechanism. The actuator 


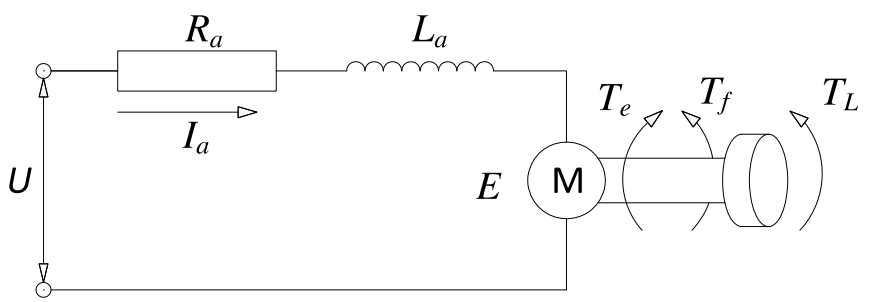

Fig. 3. Circuit diagram of DC torque motor.

includes a worm gear mechanism, a ball screw mechanism and a brake tread. Parking mechanism includes a trapezoidal screw, clamping block and linear guide.

The working principle of the brake: after voltage is applied, the torque motor runs to drive the worm gear mechanism to move, realizing the deceleration and increase of force and $90^{\circ}$ commutation of the movement. The nut in the turbine and the ball screw mechanism is fixed by a key to realize movement transmission. The movement of the nut makes the screw in the ball screw mechanism push the brake tread to move to compress the brake disc to generate brake pressure. After braking, apply voltage to the parking mechanism, and the stepper motor drives the trapezoidal screw to move, making the two clamping blocks move toward each other along the bottom linear guide to clamp the worm in the actuator.

The working principle diagram of the torque motor is established, According to the working principle of the brake. There are resistance and inductance inside the DC torque motor. The simplified circuit diagram is shown in Figure 3:

The mathematical expression is as follows:

$$
U=I_{a} R_{a}+L_{a} \dot{I}_{a}+K_{e} \omega_{m}
$$

Among them, $U$ : Armature voltage; $I_{a}$ : Armature current; $R_{a}$ : Armature resistance; $L_{a}$ : Armature inductance ; $K_{e}$ : Back EMF Coefficient; $\omega_{m}$ : Angular speed of motor rotor. The dynamic equation when the rotor is running is:

$$
\begin{gathered}
T_{e}=K_{T} I_{a} \\
T_{f}=B_{m} \omega_{m} \\
J_{m} \ddot{\theta}_{m}=T_{e}-T_{f}-T_{L} .
\end{gathered}
$$

Among them, $T_{e}$ : Electromagnetic torque; $K_{r}$ : Torque constant; $J_{m}$ : Motor moment of inertia; $\theta_{m}$ : Motor rotation angle; $T_{f}$ : Motor damping torque; $T_{L}$ : Load torque; $B_{m}$ : Motor damping. When the motor is locked, the angular velocity is zero. The pressing force of the brake shoe against the brake disc is $f_{N}$, and the transmission efficiency of the ball screw pair is $\eta_{c}$. Then the relationship between the pressure of the brake disc and the load of the nut push rod is:

$$
f_{N}=f \eta_{c}
$$

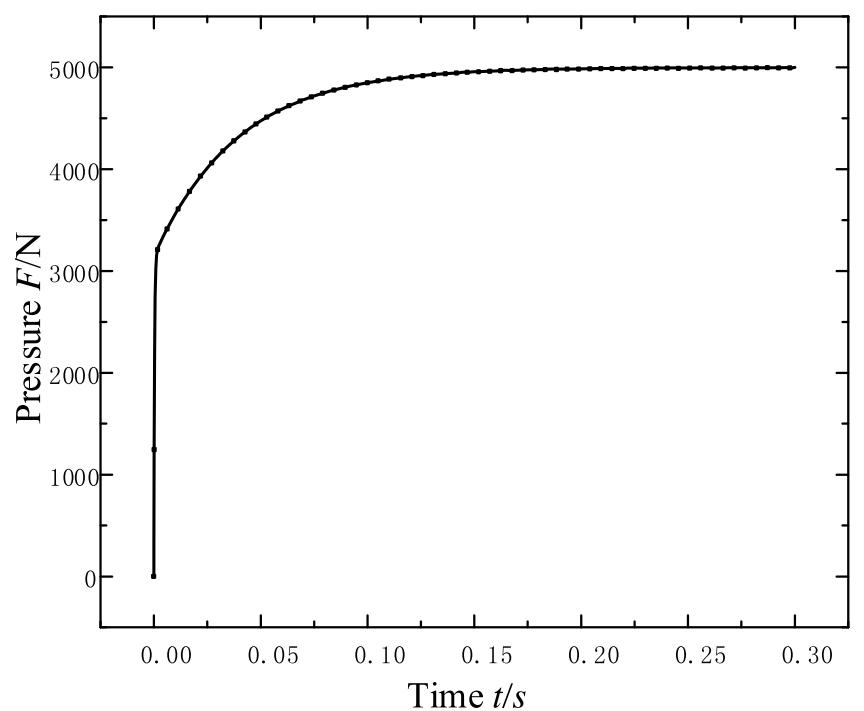

Fig. 4. Braking force response curve.

From (1), (2), (3), (4) and (5), we can get:

$$
U=\frac{L_{a}}{K_{T} i_{c} i_{v} \eta_{c} \eta_{v}} \dot{f}_{N}+\frac{R_{a}}{K_{T} i_{c} i_{v} \eta_{c} \eta_{v}} f_{N} .
$$

Carrying out the Laplace transform of (6) to get:

$$
G(s)=\frac{F(s)}{U(s)}=\frac{K_{T} i_{c} i_{v} \eta_{c} \eta_{v}}{L_{a} s+R_{a}}
$$

The pole of the open-loop transfer function is located in the left half of the complex plane, and PI control is added to the system. The braking force response curve is shown in Figure 4, Braking force reaches the target pressure within $0.2 \mathrm{~s}$ and stabilizes at the target pressure, and the steadystate error is zero. The results show that the PI controller can stabilize the positive brake pressure at the target value, providing a theoretical basis for the test.

In order to meet the actual needs, the parameters of designed brake related parts are shown in the following Table 1.

\subsection{Design and development of electromechanical brake}

There are three structures for the braking system of the mine hoist. As shown in Figure 5a, a block brake that uses brake pads to press on the brake wheel to achieve braking. As shown in Figure 5b, the electric braking system that controls the electric state of the motor to achieve braking. As shown in Figure 5c, Disc brake system working principle is that the hydraulic oil is input from the oil inlet $\mathrm{P}$ to drive the piston to move to the right and compress the disc spring to complete the brake release [23]. When the hydraulic oil is released, the disc spring is reset to push the brake. The shoe 
Table 1. Parts parameter table.

\begin{tabular}{llll}
\hline & Material name & Allowable shear stress & Allowable bending stress \\
\hline Ball screw: screw & 45 steel & $60 \mathrm{Mpa}$ & $110 \mathrm{Mpa}$ \\
Ball screw: Nut & Cast tin bronze & $30 \mathrm{Mpa}$ & $40 \mathrm{Mpa}$ \\
Worm & 45 steel & $60 \mathrm{Mpa}$ & $110 \mathrm{Mpa}$ \\
Turbine & $\mathrm{ZCuAl}_{0} \mathrm{Fe}_{3}$ & - & $58 \mathrm{Mpa}$ \\
Trapezoidal screw & 45 steel & $60 \mathrm{Mpa}$ & $110 \mathrm{Mpa}$ \\
\hline
\end{tabular}

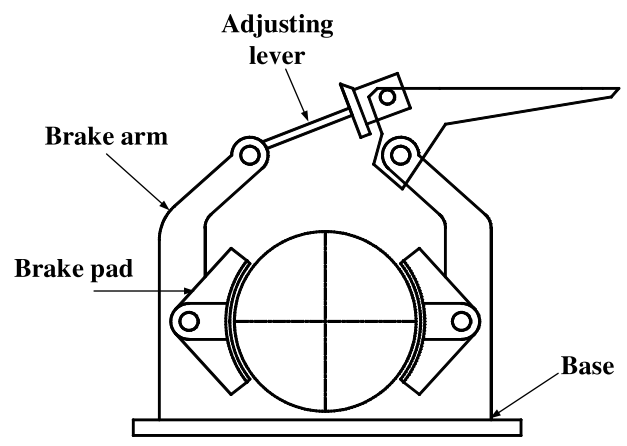

a

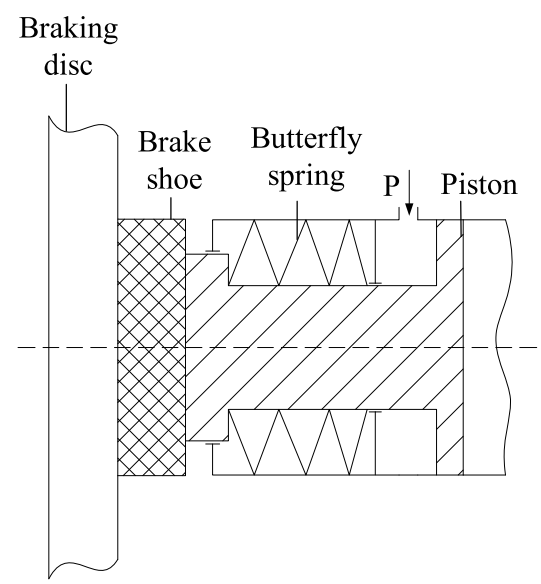

c

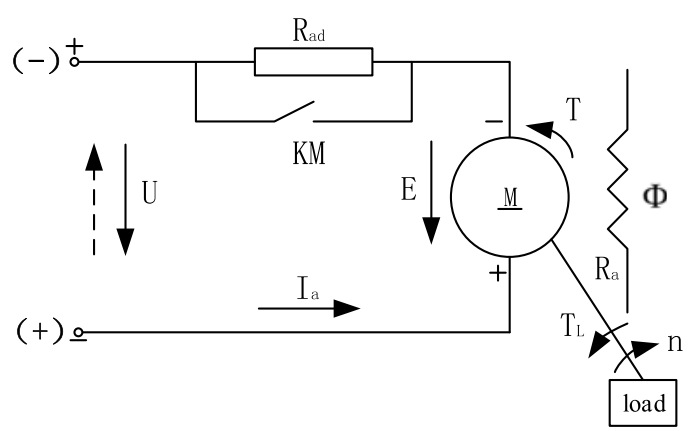

b

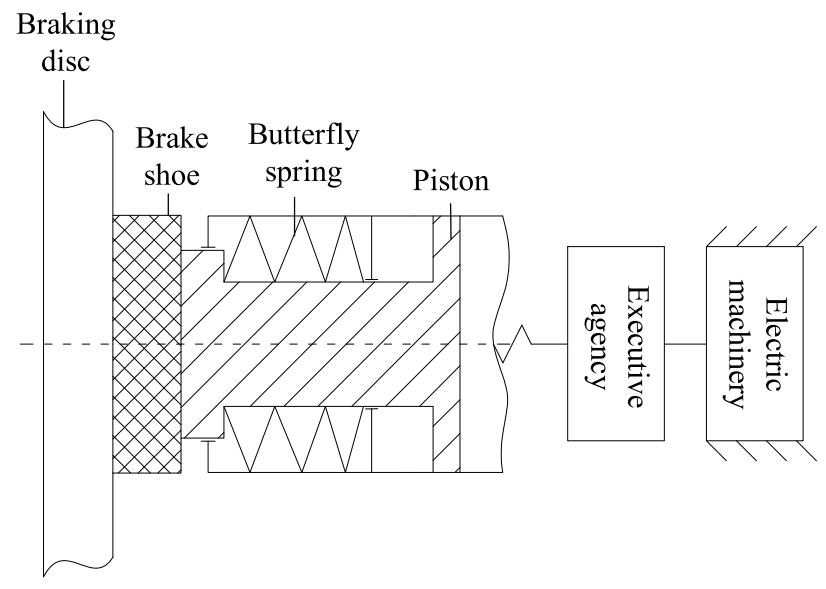

d

Fig. 5. Brake structure diagram. a. Block brake. b. Schematic diagram of electric braking. c. Hydraulic brake. d. Electro mechanical braking.

presses the brake disc to complete the braking work. Compared with the former two, the disc brake has the following advantages, so it has been widely used in mine hoisting equipment.

- The execution unit has a simple structure and is easy to replace and repair the brake pads.

- There is no afterburner, so there will be no difference between the left and right brakes, and it is not easy to pull to the other side due to unilateral braking.

- The brake has a high heat dissipation effect and rarely causes brake attenuation.

- The brake shoe gap can be self-adjusted as the brake shoe wears.
Depending on the working principle of mine hoist brakes and the parameters stipulated in Coal Mine Safety Regulations [24], the maximum brake clearance shall not exceed $2 \mathrm{~mm}$ and the clearance elimination time shall not exceed $0.3 \mathrm{~s}$. Because of ultra-deep mine hoist disc brake (the most-positive pressure is $125 \mathrm{KN}$ ), using four electromechanical brake instead of the thought of a disc brake, with a single electric mechanical brake output maximum braking pressure for $33 \mathrm{KN}, 2 \mathrm{~mm}$ brake clearance, clearance to eliminate clearance time $0.1 \mathrm{~s}$ for design direction, refer to Figure $5 \mathrm{~d}$ to complete the design of the brake, the design flow diagram is shown in Figure 6. Design and development are mainly divided into two parts: 


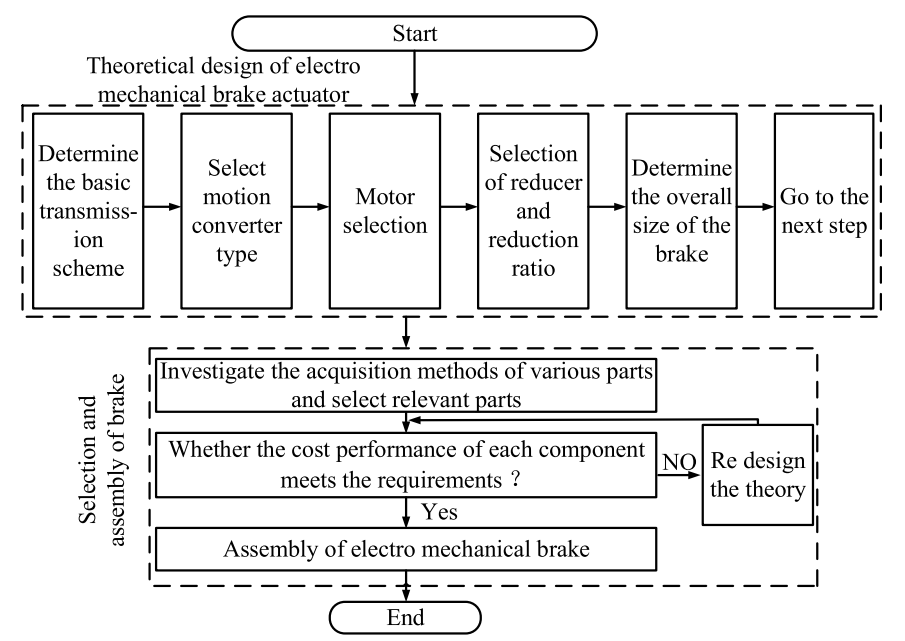

Table 2. Brake parameters.

\begin{tabular}{ll}
\hline Parameters & Numeric value \\
\hline $\begin{array}{l}\text { Maximum positive pressure } \\
\text { of brake disc } / \mathrm{KN}\end{array}$ & 33 \\
Ball screw lead $/ \mathrm{mm}$ & 10 \\
Gear reduction ratio & 8 \\
$\begin{array}{l}\text { Continuous locked-rotor torque } \\
\text { of the motor } / \mathrm{N} \cdot \mathrm{m}\end{array}$ & 8.25 \\
Peak blocking torque of motor $/ \mathrm{N} \cdot \mathrm{m}$ & 22.2 \\
\hline
\end{tabular}

Fig. 6. Design and development process of brake.

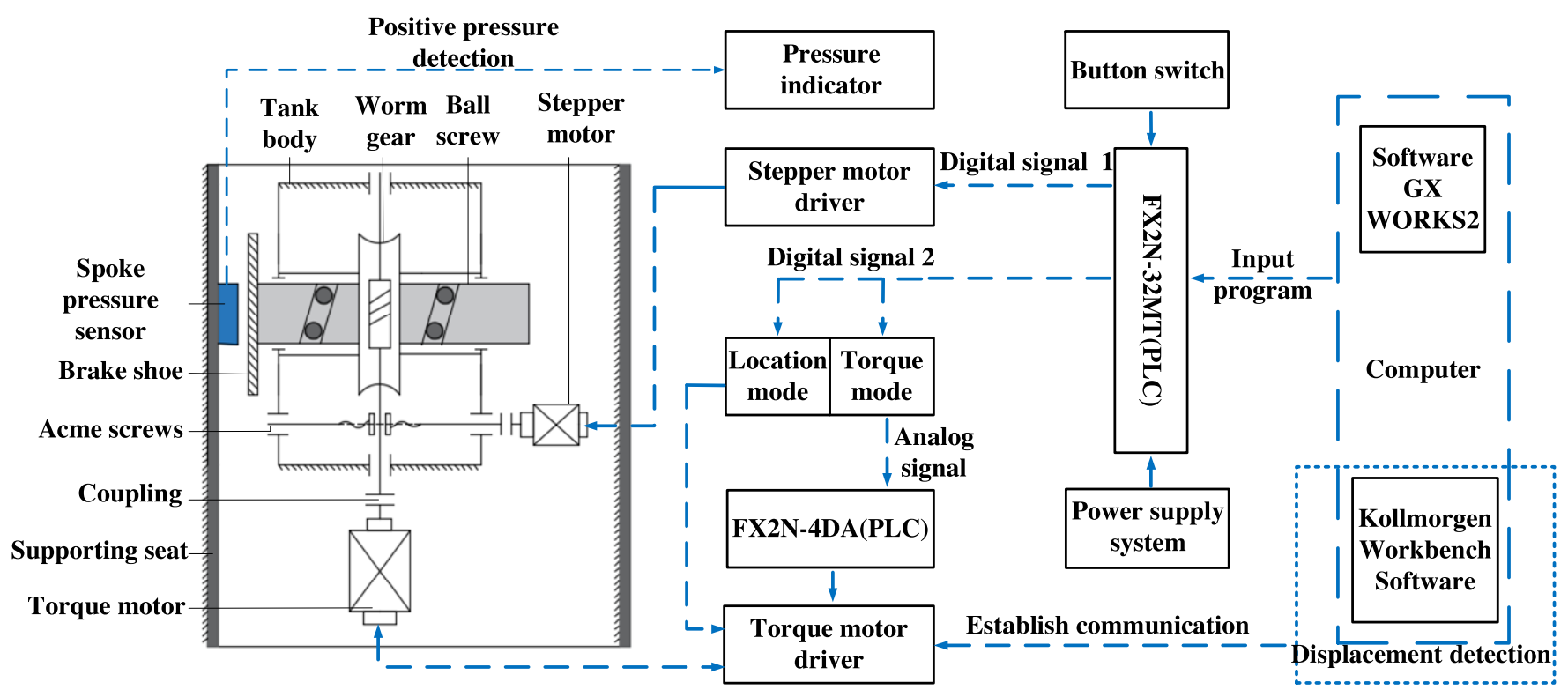

Fig. 7. Schematic diagram of electromechanical brake experimental system.

theoretical design, selection and assembly. The theoretical design includes: the determination of basic transmission scheme, determination of geometric parameters, motor selection, determination of geometrical parameters and reduction ratio of worm gears in reducer device, draw the assembly drawing to determine the rationality of the overall size. Selection and assembly mainly include the selection of materials for each component purchase and assembly. The parameters of the designed brake are shown in Table 2.

\section{Design of experiment system}

The brake experiment system mainly includes the electric control experiment of the actuator and the electric control experiment of the parking mechanism. It can be shown in Figure 7, the power supply system adopts AC $220 \mathrm{~V}$ to DC
$24 \mathrm{~V} 1.5 \AA$ A rectifier transformer (Hangzhou Ke Rui Ming Wei power supply, model: LRS Series), and the safety of circuit is protected by the circuit breaker air switch (De Li $\mathrm{Xi}$, model HDBE). The power of the actuator is provided by Kollmorgen servo torque motor (Beijing advanced control technology, model: C024A), Kollmorgen servo torque motor and Kollmorgen servo torque motor driver (Beijing High Control Technology, model: AKD-0060X) and turbo worm (customized model size) and ball screw pair (customized model size) as the driving mode, Use Mitsubishi series PLC main control module (Guangzhou Xin Feng Automation, model: FX2N-32MT) and analog module (Mitsubishi Electric Taizhou store, model: FX2N$4 \mathrm{AD} / 4 \mathrm{DA})$ to control the motor to complete the contact between the brake tread and the brake disc brake. The parking mechanism is driven by a stepper motor and trapezoidal screw with opposite screw rotation at left and right ends (customized model size) and linear guide rail 
Table 3. I/O address.

\begin{tabular}{llll}
\hline Address & Features & Address & Features \\
\hline Y000 & Stepper motor Pulse signal & Y004 & Torque motor Mode switching \\
Y001 & Stepper motor Direction signal & Y005 & Torque motor Enable \\
Y002 & Torque motor Homing & Y006 & Torque motor Torque mode \\
Y003 & Torque motor Location mode & Y007 & Torque motor Reverse reset \\
\hline
\end{tabular}

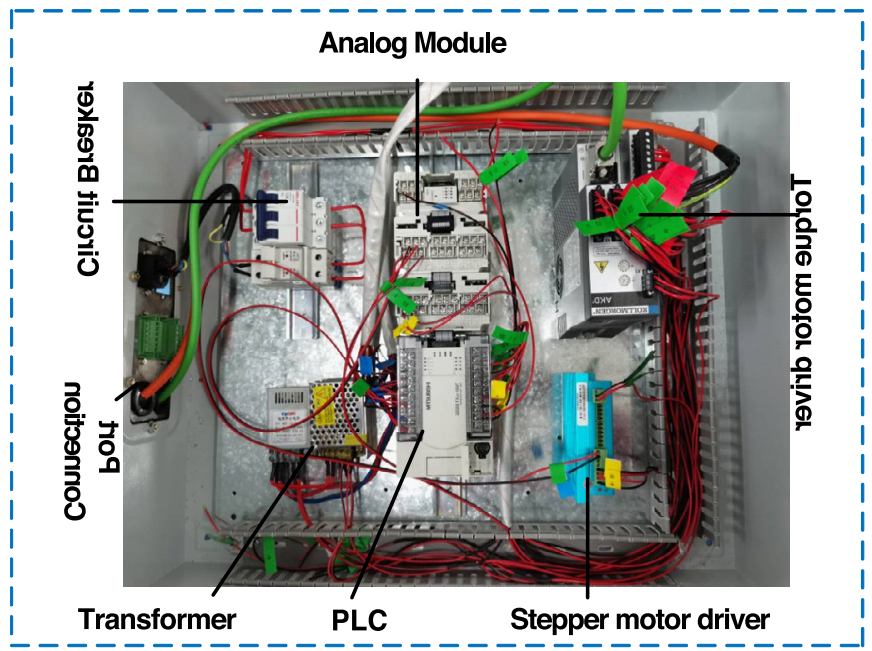

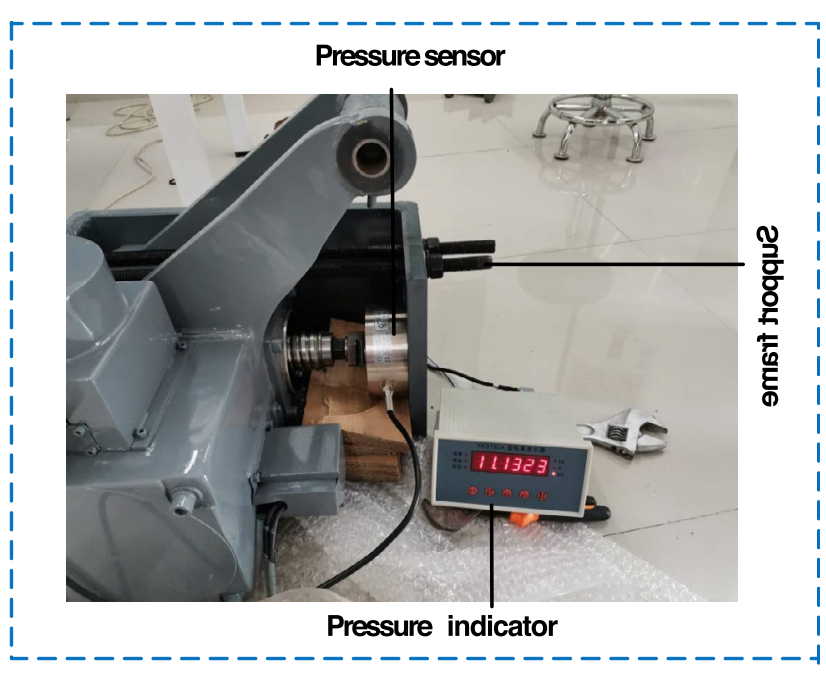

$\mathrm{b}$

Fig. 8. Site photo of electromechanical brake test device. a. Internal control circuit. b. Electro mechanical brake.

(customized model size) and clamp block (customized model size), the power of the mechanism is provided by a stepper motor (Shanghai Zheng Ji, J-5718HBS2401), and by PLC to the stepper motor issues control instructions to control the motor running direction and then control the operation of the mechanism. Parking will be completed when the motor is turning forward, and the parking task will end when the motor is reversing.

The actuator in the brake is controlled by establishing the communication between the driving software (Kollmorgen Workbench) and the torque motor drive, and the communication between the programming software (GX Works 2) and the PLC, and the programming software is used to input control program into PLC. The program mainly includes controlling the enable, homing, switching between the position mode and the torque mode of the torque motor, and the forward and reverse rotation of the torque motor. When the torque motor rotates forward, the screw rod rotates, and drives the brake tread to press the brake disc to complete the braking. Conversely, the screw drives the brake disc to move away from the brake disc to release the brake. Start the control program, the brake actuator starts to work, relying on the spoke pressure sensor and the weighing display to monitor the value of the positive pressure generated by the brake in real time, and the driving software displays the displacement of the screw in real time. The parking mechanism is controlled by establishing communication between PLC and stepper motor driver, and input pulse command and direction command from PLC to stepper motor driver. Pulse command controls motor speed, direction command controls motor forward and reverse, the forward rotation of the motor drives the rotation of the trapezoidal screw, so that the clamping block clamps the worm to complete the parking, and the reverse ends the parking task. Among them, the main function address allocation of output relay $\mathrm{Y}$ in the programmable controller PLC is shown in Table 3.

Taking into account that in the actual braking process, the friction coefficient between the brake shoe and the brake disc will change due to friction and heat, which will affect the braking performance of the brake. At the same time, the designed brake is still in the experimental test stage, and the field test may cause safety accidents. Therefore, the temperature effect is not considered during the experiment.

To verify that the electromechanical brake structure and brake experimental system designed in this paper are practical and feasible. After ensuring the correct wiring of the circuit and the correct installation of mechanical parts, the brake experiment device built is shown in Figure 8. Due to experimental conditions, a support base (marked in Fig. 8) was designed and processed, and the brake mechanism was fixed on it by bolts, and one end of the spoke sensor was fixed to the support base. Two locking studs are installed outside the support base to avoid excessive deformation of the support base due to excessive 
Positive stroke



Reverse stroke



Fig. 9. Experiment flow chart.

Table 4. Motor current input and positive pressure output test results.

\begin{tabular}{|c|c|c|c|c|c|c|c|c|c|c|c|c|}
\hline \multirow{2}{*}{ First trial } & Input current $/ \AA$ & 0.2 & 0.72 & 0.81 & 1.36 & 1.93 & 2.47 & 2.68 & 3.08 & 3.35 & 3.6 & 4.6 \\
\hline & Out positive pressure/KN & 1.37 & 3.71 & 5.05 & 6.45 & 9.35 & 10.68 & 12.23 & 13.81 & 15.41 & 16.9 & 20.1 \\
\hline \multirow[b]{2}{*}{ Second test } & Input current $/ \AA$ & 0.19 & 0.65 & 0.84 & 1.12 & 1.32 & 2.19 & 2.39 & 2.87 & 3.7 & 4.07 & 4.8 \\
\hline & Out positive pressure/KN & 1.48 & 2.74 & 4.09 & 5.5 & 6.99 & 10.09 & 11.7 & 13.37 & 16.5 & 18.01 & 21.5 \\
\hline \multirow[b]{2}{*}{ Third trial } & Input current/ $\AA$ & 0.21 & 0.69 & 0.82 & 1.2 & 1.65 & 2.38 & 2.53 & 2.96 & 3.44 & 3.86 & 17.42 \\
\hline & Out positive pressure/KN & 1.52 & 3.25 & 4.86 & 6.24 & 8.42 & 10.47 & 12.02 & 13.42 & 15.61 & 17.42 & 20.4 \\
\hline \multirow[b]{2}{*}{ Fourth test } & Input current/ $\AA$ & 0.2 & 0.68 & 0.82 & 1.24 & 1.62 & 2.33 & 2.53 & 3.02 & 3.56 & 3.83 & 4.8 \\
\hline & Out positive pressure/KN & 1.42 & 3.32 & 4.57 & 5.97 & 8.17 & 10.38 & 11.96 & 13.64 & 15.81 & 17.39 & 20.8 \\
\hline
\end{tabular}

positive pressure, which will affect the accuracy of the measured experimental data, in order to save experimental cost, the device uses a vise to manually clamp the screw rod to ensure that the screw rod will not rotate with the rotation of the nut during the operation of the device.

\section{Experimental analysis and discussion}

Based on the completed test bench, in order to master the basic working characteristics of electro-mechanical brake, it is necessary to carry out tests so as to intuitively understand the real working condition of the brake and verify whether it can work normally according to the design requirements. The experiment flow chart is as follows in Figure 9.

In addition, the acceleration and deceleration of the hoist are generally controlled by the electronic control system, and the disc brake is equivalent to the auxiliary braking device. In the case of emergency braking, the hoist completely relies on disc brakes for holding brakes. The electromechanical brake developed in the article was originally designed as an auxiliary braking device, but the brake is still in the test stage, and there are still many issues that have not been considered, such as temperature effects, electromagnetic field and temperature field coupling related issues, comprehensive considerations cannot be carried out temporarily. If the field test is carried out, it may cause a safety accident, so the field test will be carried out after the brake is mature.

During emergency braking, the disc brake will generate a lot of friction heat in the friction area of the brake disc, causing the local temperature of the friction area to rise and generate thermal stress. Under the cyclic action of friction, thermal stress and brake pressure, the surface of the brake disc is prone to thermal fatigue damage, resulting in thermal fatigue cracks and reducing the braking capacity of the brake disc. The starting point for the design of the brake in the article is that the device can meet the maximum braking force and the mechanical requirements of coal mine safety regulations. The sensor used during the test directly measures the positive pressure. Therefore, the temperature effect will be carefully examined in future work study.

\subsection{The relationship between motor current input and brake pressure output}

The brake tread is in contact with the sensor before the start of the experiment, and the input voltage of the torque motor is changed by changing the analog quantity in the program, so that the brake tread pressed the pressure sensor under different input currents. The relationship between the motor current and the positive pressure of the brake is obtained. In the experiment, because of the static friction torque between the motor and the worm gear reducer, the initial operating current of the electromechanical brake reaches $3 \AA$, this article sets up 4 groups of experiments and takes the average value after removing the initial current from the 4 groups of experimental data. The experimental results are shown in Table 4.

By observing the distribution of the experimental data in the coordinate system shows that the torque motor current has a linear relationship with the positive pressure, so the first-order fitting is used for the average data, the fitted curve is shown in Figure 10. 


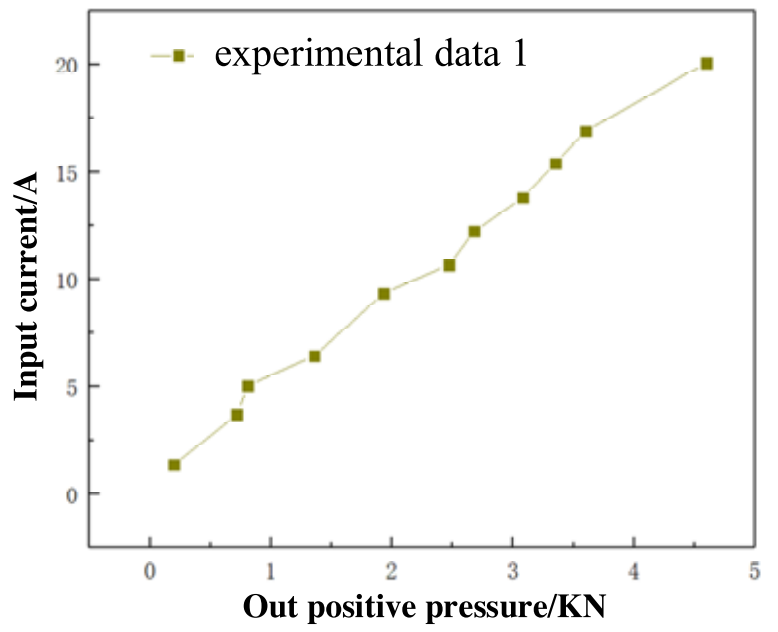

a

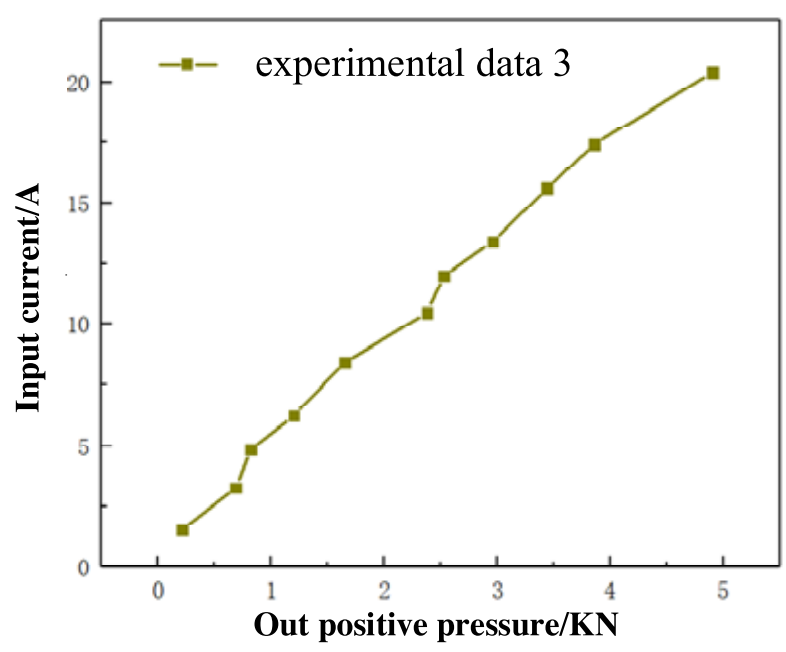

c

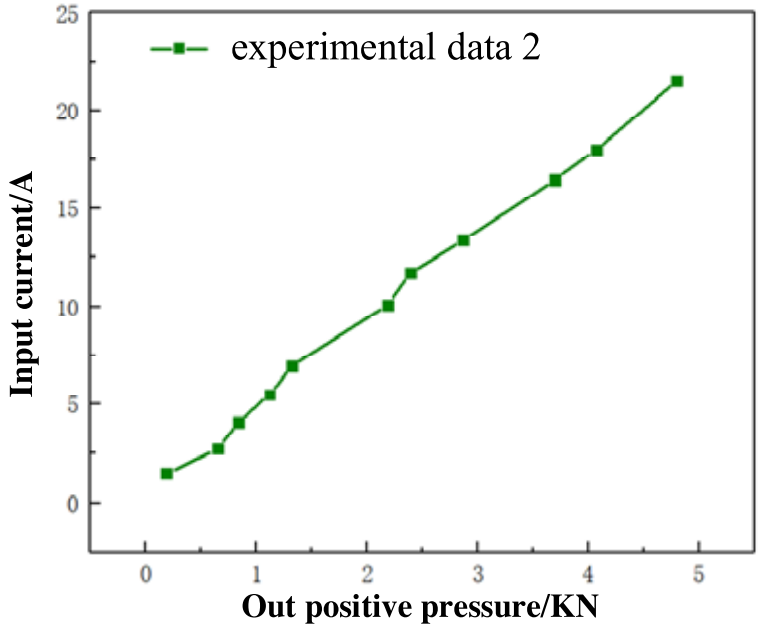

b

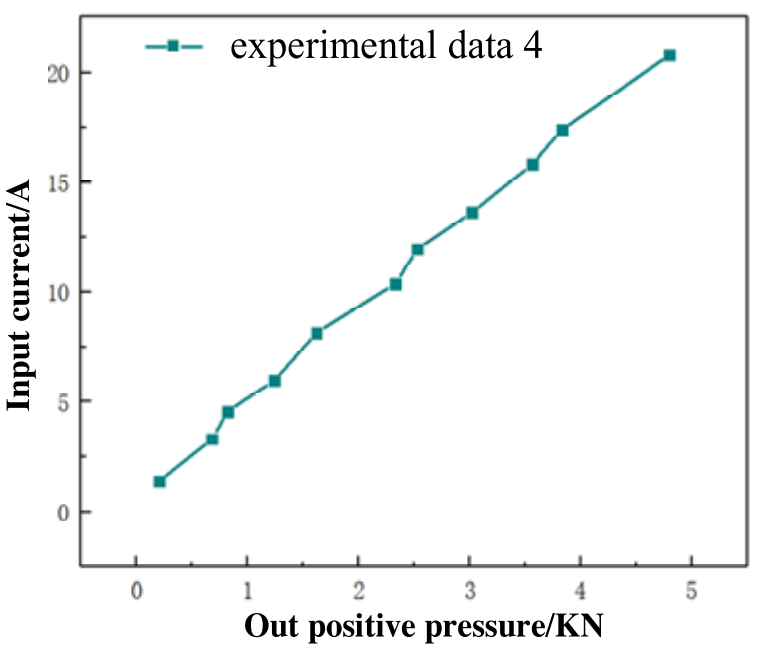

d

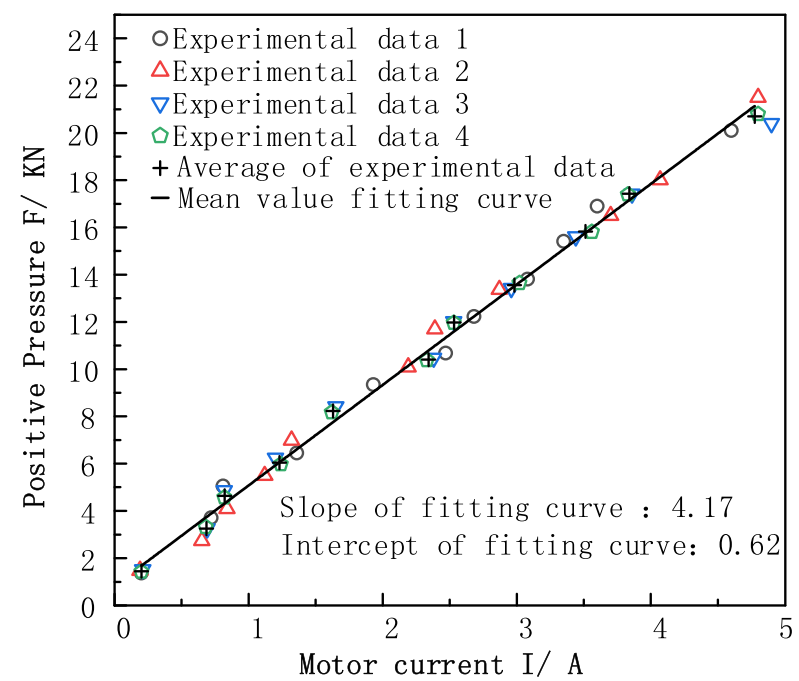

e

Fig. 10. Relation curve of motor current input and output positive pressure. a. First trial. b. Second trial. c. Third trial. d. Fourth trial. e. Mean value fitting curve. 
Table 5. Test results of lead screw displacement output and brake pressure output.

\begin{tabular}{ll}
\hline Screw displacement/mm & Positive pressure/KN \\
\hline 0.05 & 0.19 \\
0.1 & 0.457 \\
0.15 & 1.667 \\
0.2 & 2.32 \\
0.25 & 3.26 \\
0.3 & 4.38 \\
0.35 & 5.62 \\
0.4 & 6.89 \\
0.45 & 8.28 \\
0.5 & 9.70 \\
\hline
\end{tabular}

It can be seen from Figure 10e that the slope of the fitting line is 4.17 and the intercept is $0.62 \mathrm{KN}$, the fitting curve formula is as follows:

$$
F=4.17 I+0.62
$$

In the formula: $F$ is the positive pressure output by the brake, symbol $I$ stand for the motor current. From formula (8), the motor current and the positive pressure force are linear. When the current is zero, the braking force is $0.62 \mathrm{KN}$, the positive pressure force generated when the brake tread contacts the pressure sensor before the experiment starts, which conforms to the actual situation.

\subsection{Relationship between screw displacement output and brake pressure output}

The designed brake braking process consists of two parts, one is the no-load feed to eliminate the gap between the brake shoe and the brake, and the other is the contact between the brake shoe and the brake disc to achieve locked rotor. The brake disc will inevitably be deformed during the blocking process, and the amount of deformation is not easy to measure and cannot be calculated. Therefore, the relationship between displacement and brake pressure can only be obtained by fitting the data measured by the test.

In the experiment, the computer applies instructions to the programmable controller PLC, so that the torque motor rotates to drive the screw to move and compress the spoke sensor. In each experiment, the displacement of the control screw is constant, and each experiment is carried out in 5 groups. The average value of the test results is shown in Table 5.

Observing the distribution of experimental data in the coordinate system, it can be seen that the screw displacement and the positive pressure are not linear. Therefore, it is necessary to shape higher-order curve fitting, and it is found that the third-order fitting curve is more realistic during fitting. The fitting curve is shown in Figure 11.

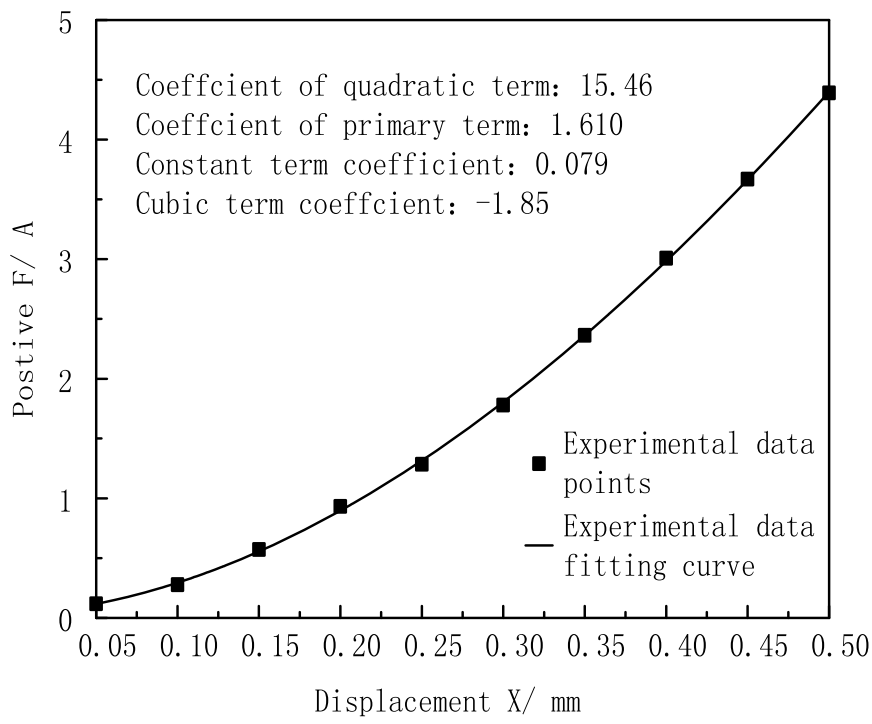

Fig. 11. 3rd-order fitting curve of screw displacement and output positive pressure.

The positive pressure and the screw displacement have a cubic relationship is shown in Figure 11, and the fitting curve formula is as follows:

$$
F=-1.85 X^{3}+15.46 X^{2}+1.61 X+0.079 .
$$

In formula (9): $\mathrm{F}$ is the brake output positive pressure, $\mathrm{X}$ is the screw rod displacement, When the displacement is zero, the positive pressure is $0.079 \mathrm{KN}$, because the zero error is $0.02 \%$, the error can be ignored.

\subsection{Maximum positive pressure test}

In the maximum positive pressure test experiment, the servo torque motor receives the position mode command sent by the computer, so that the brake tread can eliminate $2 \mathrm{~mm}$ brake gap in $0.1 \mathrm{~s}$. Then the motion mode of torque motor is switched from position mode to torque mode, in torque mode, the screw drives the brake tread to compress the spoke sensor, and record the positive pressure force value displayed on the display. It can be estimated from equation (8), when the output current is $7.76 \AA$, the positive pressure is $33 \mathrm{KN}$. When the output current is $3.49 \AA$, the positive pressure is $11.35 \mathrm{KN}$. Therefore, the brake input current is set at $7.76 \AA$ and $2.49 \AA$, respectively. The relationship chart between maximum pressure and braking time is obtained by experiment.

It can be seen from Figure 12 that when the current is $2.49 \AA$ and $7.76 \AA$, the brake gap can be eliminated within $0.1 \mathrm{~s}$, which shows that the electro-mechanical brake can meet the braking requirements of mine hoist to eliminate the brake clearance within $0.3 \mathrm{~s}$. Comparing the two curves in the figure, when the current is bigger, the positive pressure force increases faster and the time to reach the target positive pressure is shorter, which verifies the accuracy of the linear relationship obtained by the fitting. After a period of time, the curve showed a slow downward trend and gradually stabilized, the average value of the 


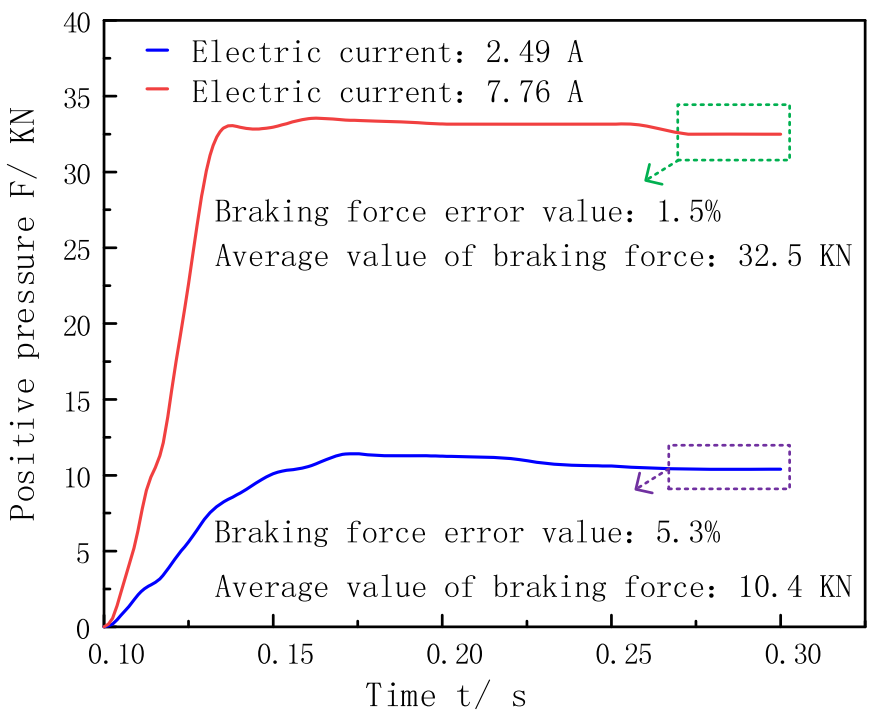

Fig. 12. Curve of positive pressure force change.

positive pressure force at stability is $32.5 \mathrm{KN}$, and the error is $1.5 \%$. When the current is $2.49 \AA$, the change trend of braking force is similar to that of $7.76 \AA$, and the average value of the final stable positive pressure force is $5.4 \%$, both are within $10 \%$.

\section{Conclusion}

When facing deep coal mining, the response characteristics of the hydraulic disc brake in the traditional hoisting system cannot meet the needs of ultra-deep mine hoisting. However, the developed ultra-high pressure coal mine brake system still has problems in improving the braking response and improving the reliability of the system. As a reserve scheme, a kind of braking technology controlled by electric is studied, so that the set of braking objects becomes an electric control system controlled in real time.

The test results show that the relationship between brake current input and positive pressure output is linear, and the relationship between screw displacement output and brake positive pressure output is cubic and the greater the brake input current, the faster the braking force rises. When the input current is $7.76 \AA$, the braking gap can be eliminated within $0.1 \mathrm{~s}$, and the positive pressure can reach $35 \mathrm{KN}$ in a short time. When it becomes stable, the braking force can reach $32.5 \mathrm{KN}$ with an error of $1.5 \%$, which can meet the requirements of ultra-deep mines. The disc brake of the hoist (maximum positive pressure $125 \mathrm{KN}$ ) is the reference object, and the original design intention of using 4 electromechanical brakes (single $33 \mathrm{KN}$ ) instead of disc brake. It meets the maximum positive pressure requirements of electromechanical brakes of mine hoists, and is highly compatible with the development direction of deep coal intelligent equipment.

\section{Funding}

This work was supported by the National Foundation of China (Grant NO.:51904009), the National Key R \& D
Program of China (Grant NO.: 2020YFB1314103), the Outstanding Young Talents Program of Anhui University of China (Grant NO.: gxyq2019022), the Institute of Environment-friendly Materials and Occupational Health (Wuhu), Anhui University of Science and Technology (Grant NO.: ALW2020YF17), the Development Fund of State Key Laboratory for Green and Safe Coal Development in Western China (Grant NO.: SKLCRKF20-14), the Anhui University of science and Technology Launched Research Fund.

Conflicts of interest. The authors declare no conflict of interest.

\section{Nomenclature}

$\begin{array}{ll}\mathrm{P} & \text { Oil inlet } \\ \mathrm{PLC} & \text { Programmable Logic Controller } \\ \mathrm{F} & \text { Positive pressure } \\ \mathrm{I} & \text { Motor current } \\ \mathrm{X} & \text { Screw displacement } \\ \mathrm{U} & \text { Armature voltage } \\ \mathrm{R}_{\mathrm{ad}} & \text { Additional resistance } \\ \mathrm{KM} & \text { Additional resistance } \\ \mathrm{E} & \text { Electrodynamic force } \\ \mathrm{I}_{\mathrm{a}} & \text { Armature current } \\ \mathrm{R}_{\mathrm{a}} & \text { Resistance } \\ \mathrm{T} & \text { Electromagnetic torque } \\ \mathrm{T}_{\mathrm{L}} & \text { Load torque } \\ \mathrm{n} & \text { Speed } \\ \Phi & \text { Magnetic flux }\end{array}$

\section{Author contribution statement}

Conceptualization, HW.J. and HY.H.; data curation, HW. J. and HY.H.; formal analysis, HW.J. and HY.H.; funding acquisition, HW.J. and CL.W.; investigation, HY.H, S.W. and HW.X.; methodology, HW.J. and HY.H.; project administration, HW.J.; resources, HW.J. and HW.X.; software, HY.H.; supervision, HW.J. and S.W.; validation, HY.H. and HW.J.; writing - original draft preparation, S H; writing review and editing, HY.H., HW.J. and CL.W.

\section{References}

[1] G.F. Wang, H. Wang, H. Ren et al., Smart coal mine 2025 scenario goal and development path, J. Coal Ind. 43, 295-305 (2018)

[2] H.T. Zhang, Y.J. Dai, Y.J. Jia, The design of disc brake for mine hoist in civil engineering, Adv. Mater. Res. 1943, 212-215 (2012)

[3] Q. Wang, C. Zhang, Q. Shuang, The study on electrohydraulic proportional relief valve of disc braking system based on AMESim, in International Conference on Intelligent Systems Research \& Mechatronics Engineering (2015)

[4] X.F. Wang, X.M. Xiao, X.Y. Zhang, Research for dynamic characteristics of electro-hydraulic proportional relief valve based on AMESim, Adv. Mater. Res. 466-467, 518-522 (2012) 
[5] M. Ungureanu, N. Ungureanu, Wear intensity of mine hoist brake materials, Tehnički Vjesnik 24, 585-589 (2017)

[6] M. Kumar, X. Boidin, Y. Desplanques et al., Influence of various metallic fillers in friction materials on hot-spot appearance during stop braking, Wear 270, 371-381 (2011)

[7] D. Wang, R. Wang, J. Zhang, Dynamic brake characteristics of disc brake during emergency braking of the kilometer deep coal mine hoist, Adv. Mech. Eng. 12, 1-23 (2020)

[8] D. Wang, J. Yin, Z. Zhu, Preparation of high friction brake shoe material and its tribological behaviors during emergency braking in ultra-deep coal mine hoist, Wear 458, 203391 (2020)

[9] Y. Zhang, G. Xu, X. Zhang, Design and research of the disc brake of mine hoists for monitoring the disc spring force and positive brake pressure, Measur. Sci. Technol. 30, 25903 (2019)

[10] G. Xu, D. Song, D. Zhang, A novel mechanical design of disc brakes for fault diagnosis and monitoring positive braking pressure in mine hoist, Adv. Mech. Eng. 11, 1-16 (2019)

[11] Z. Jiao, X. Zhang, Y. Shang, A power-by-wire aircraft brake system based on high-speed on-off valves, Aerospace Sci. Technol. 106, 106177 (2020)

[12] J. Deng, K. Hu, B. Lu, Influence of B 4C on oxidation resistance of PSN/borosilicate Glass-B 4C field-based repair coating of $\mathrm{C} / \mathrm{C}$ aircraft brake materials at $700-900{ }^{\circ} \mathrm{C}$, Ceram. Int. 45, 20860-20872 (2019)

[13] C. Zhang, L. Zhang, Q. Zeng, Simulated three-dimensional transient temperature field during aircraft braking for $\mathrm{C} / \mathrm{Si}$ C composite brake dis, Mater. Des. 32, 2590-2595 (2011)

[14] S. Wolny, Braking distance of hoist conveyances required for safe stopping under the conditions of emergency braking, Arch. Min. Sci. 62, 279-288 (2017)
[15] X. Wei, Q. Yin, H. Nie et al., Aircraft electric anti-skid braking system based on fuzzy-PID controller with parameter self-adjustment feature, Trans. Nanjing Univ. Aeronaut. Astron. 31, 111-118 (2014)

[16] A. Trentin, P. Zanchetta, P. Wheeler, J. Clare, Power flow analysis in electro-mechanical actuators for civil aircraft, Iet Electric Power Appl. 5, 48-58 (2011)

[17] Y. Hye, Ryu, M. Ki, Implementation of Electro-Mechanical Brake (EMB) for brake-by-wire system of electric vehicle, J. Korean Soc. Ind. Converg. 20, 313-323 (2017)

[18] L. Chris, M. Chris, G. Malcolm, Control of an electromechanical brake for automotive brake-by-wire systems with an adapted motion control architecture, SAE Technical Paper (2004)

[19] G. Park, S. Choi, Clamping force control based on dynamic model estimation for electro-mechanical brakes, J. Automobile Eng. 232, 2000-2013 (2018)

[20] C. Lee, C. Manzie, Active brake judder attention using an electromechanical brake-by-wire system, IEEE-ASME Trans. Mech. 21, 2964-2976 (2016)

[21] M. Atia, S. Haggag, A. Kamal, Enhanced electro-mechanical brake-by-wire system using sliding mode controller, J. Dyn. Syst. Measur. Control 138, 041003 (2016)

[22] B. Sababha, Y. Alqudah, A reconfiguration-based faulttolerant anti-lock brake-by-wire system, ACM Trans. Embedded Comput. Systems (TECS) 17, 1-13 (2018)

[23] K. Park, S. Heo, A study on the brake-by-wire system using hardware-in-the-loop simulation, Int. J. Vehicle Des. 36, 38-49 (2004)

[24] W. Andrew, Homer, Coal mine safety regulation in China and the USA, J. Contemp. Asia 39, 424-439 (2009)

Cite this article as: H. Jin, H. Huo, C. Wang, S. Wang, H. Xu, Design and experimental study of electrical and mechanical brake for mine hoist, Mechanics \& Industry 22, 36 (2021) 